\title{
The use of an e-tongue for discriminating ethanol/water mixtures and determination of their water content
}

\author{
Dalton P. de Queiroz ${ }^{\mathrm{a}, \mathrm{e}}$, Ariovaldo de Oliveira Florentino ${ }^{\mathrm{b}, 1}{ }$, Juliana Catarina Bruno ${ }^{\mathrm{b}}$, \\ José H. Dias da Silva ${ }^{c}$, Antonio Riul Jr. ${ }^{\mathrm{d}, \mathrm{e}}$, José A. Giacometti ${ }^{\mathrm{e}, \mathrm{f}, *}$ \\ a Universidade Estadual de Mato Grosso do Sul, UEMS, 79804-970, Dourados, MS, Brazil \\ b Instituto de Biociências, UNESP, 18.618-000 Botucatu, SP, Brazil \\ c Faculdade de Ciências, UNESP, 17.033-360, Bauru, SP, Brazil \\ ' Instituto de Física Gleb Wataghin,UNICAMP, 13083-859, Campinas, SP, Brazil \\ e Faculdade de Ciências e Tecnologia, UNESP, 19060-900 Presidente Prudente, SP, Brazil \\ ${ }^{\mathrm{f}}$ Instituto de Física de São Carlos, USP, 13566-590 São Carlos, SP, Brazil
}

\section{A R T I C L E I N F O}

\section{Article history:}

Received 9 September 2015

Received in revised form

24 December 2015

Accepted 18 February 2016

Available online 22 February 2016

\section{Keywords:}

Electronic tongue

Ethanol biofuel

Ethano-water mixture

Principal component analysis

\begin{abstract}
A B S T R A C T
This paper discusses the applicability of an electronic tongue (e-tongue) based on capacitance measurements to determine the water content in ethanol. The e-tongue consisted of an array of interdigitated electrodes coated with ultrathin films of gallium nitrate and titanium dioxide, which were robust against attack by ethanol. Principal Component Analysis (PCA) was used to treat the capacitance data for discriminating ethanol/water mixtures even in cases with very small water contents. Discrimination is easier if the water added to ethanol contains ions, as is the case of tap water or if $\mathrm{NaCl}$ is added to the mixtures. With this e-tongue we were able to quantify the water content through a linear relationship between the first principal component (PC1) and the added water to the biofuel. Therefore, we have proven to be possible to measure the water content precisely, which is one of the major problems in ethanol biofuel adulteration nowadays.
\end{abstract}

(c) 2016 Elsevier B.V. All rights reserved.

\section{Introduction}

According to IUPAC definition an electronic tongue (e-tongue) is a multisensory system composed of low-selective sensors, using advanced mathematical techniques for signal processing based on pattern recognition and multivariate analysis [1]. These systems appeared as a suitable tool to distinguish between different complex liquid systems, as in the analysis of wine, beer, coffee, pollutants in water, food, juices, milk and mineral water [2-8]. Some advantages in comparison to conventional analytical methods include a fast, efficient and cheaper analysis, and easy interpretation of the results with no need of trained personnel. This has generated strong interest in the industry requiring quality control of foodstuff. The most used techniques in e-tongue systems are potentiometry [9-12], cyclic voltammetry [13-16], impedance spectroscopy [17-21]. They are all based on the global selectivity of sensing units immersed in a liquid sample.

\footnotetext{
* Corresponding author.

E-mail address: giacometti@ifsc.usp.br (J.A. Giacometti).

1 (in memoriam).
}

Ethanol has been an alternative biofuel produced from renewable resources with an increasing global claim as the crop carbon sequestration substantially balances the amount of carbon emitted into the atmosphere. Brazil is a leading country in the use of ethanol biofuel in flex vehicles that are able to run using ethanol, gasoline and their mixtures. In addition, anhydrous ethanol is added into gasoline in Brazil to increase the octane rating. The amount of water in the ethanol biofuel is regulated by Brazilian legislation [22]; the anhydrous ethanol fuel (AEF) must not contain more than $0.4 \%$ vol. of water, while $6.5 \%$ vol. of water is the maximum allowed for hydrous ethanol fuel (HEF). The quality control of ethanol is an important issue since the most common procedure for adulteration is addition of non-pure water above required standards, resulting in an off-specification product that can damage or produce malfunction in car engines.

Several techniques are used to measure [23] the amount of water in the ethanol biofuel, but low-cost techniques are still necessary. Bueno and Paixão [24] proposed a copper interdigitated bare electrode, which was able to determine the water content through electrical capacitance measurements at distinct frequencies. Ultrasonication was also proposed to measure water content in ethanol biofuel [25]. 
Here, we address the use of an e-tongue system to determine the water content in ethanol/water mixtures, with the challenge to build sensing units resistant to the ethanol chemical attack. A comparison was made with addition of ultrapure, tap water and sodium chloride salt solution in ethanol, and the results were processed using Principal Component Analysis (PCA). We also address the possibility to measure the water content in ethanol biofuel.

\section{Experimental}

Gold interdigitated electrodes (IDE) were deposited on glass slides consisting of 50 pairs of digits $5 \mathrm{~mm}$ long, $10 \mu \mathrm{m}$ width, separated $10 \mu \mathrm{m}$ from each other. Four sensing units were used: one bare IDE and three electrodes coated with thin films of gallium nitrate $(\mathrm{GaN})$, titanium oxide $\left(\mathrm{TiO}_{2}\right)$ and titanium oxide doped with 1 mass \% of silver $\left(\mathrm{TiO}_{2}-\mathrm{Ag}\right)$. Titanium oxide and titanium oxide doped with 1 mass \% of silver were deposited by the sol-gel method [26]. Titanium isopropoxide (Agros Organics) was used as starting material and isopropyl alcohol (Mallinckrodt) as solvent. Acetic acid (J.T. Baker) and a solution of nitric acid (Merck) were added to promote the hydrolysis polycondensation reaction, where the acetic acid acted as the chelant agent in the molar rate of 1:4 (vol.) of the isopropoxide nitric acid. This sol (viscosity of $20 \mathrm{cP}$ ) was spin coated on top of the IDEs using a rotation speed of $1000 \mathrm{rpm}$, after which the electrodes were further heated and kept at $250^{\circ} \mathrm{C}$ for $12 \mathrm{~h}$, producing $200 \mathrm{~nm}$ thick films with roughness ranging from 1.7 to $3.5 \mathrm{~nm}$ in $10 \mu \mathrm{m}^{2}$, determined by AFM analysis using a Nanosurf Easy Scan AFM apparatus. Gallium nitrate was sputtered onto the IDEs in a RF-magnetron sputtering setup especially assembled to grow III-V compound semiconductor films, resulting in $\sim 60 \mathrm{~nm}$ films [27]. A metallic Ga target (7N-purity) and different N2/H2/Ar gas flow ratios (6N-purity) were used in the sputtering process. The films were uniform according to optical microscopy $(100 \times)$ images (results not shown).

Impedance spectroscopy measurements with the sensing units were performed using an impedance analyzer (Solartron 1260A) in the range between $1 \mathrm{~Hz}$ and $1 \mathrm{MHz}$, with $50 \mathrm{mV}$ of applied sinusoidal voltage. Results are given in terms of the real part of the electrical capacitance as a function of frequency. Briefly, at lower frequencies $(<100 \mathrm{~Hz})$ the electrical response is governed by double-layer effects, while at intermediate frequencies $(\mathrm{kHz}$ region) it is governed by the film coating the IDEs and at higher frequencies $(>100 \mathrm{kHz})$ by geometric capacitance effects $[28,29]$.

For the e-tongue measurements, we used a computer controlled setup [30] that allows for simultaneous use of up to eight sensing units. Responses were analyzed at $1 \mathrm{kHz}$, because capacitance measurements at this frequency are sensitive to changes in the film properties due to the liquid sample [28]. The results were analyzed with the non-supervised method of Principal Component Analysis [30] as it is largely employed in this sort of application [21]. The experimental setup performs automatically the PCA analysis, displaying it on the computer screen as a PCA plot [31]. Impedance measurements were performed immersing all sensing units in a small beaker with ethanol and ethanol/water mixtures. Measurements were taken using $10 \mathrm{~mL}$ aliquots from an initial volume of $100 \mathrm{~mL}$. For e-tongue measurements, ten readings of capacitance were performed after immersing the sensing units during $5 \mathrm{~min}$ in the liquids, which was sufficient to stabilize readings. After each measurement, the sensing units were washed with ultrapure water acquired from a Millipore Direct Q5 system model and gently dried flushing dry air. Measurements were taken at room temperature $\left(25 \pm 0.1^{\circ} \mathrm{C}\right)$, controlled by a thermostatic bath (Marconi MA-184). The same set of sensing units was employed for all measurements described here.

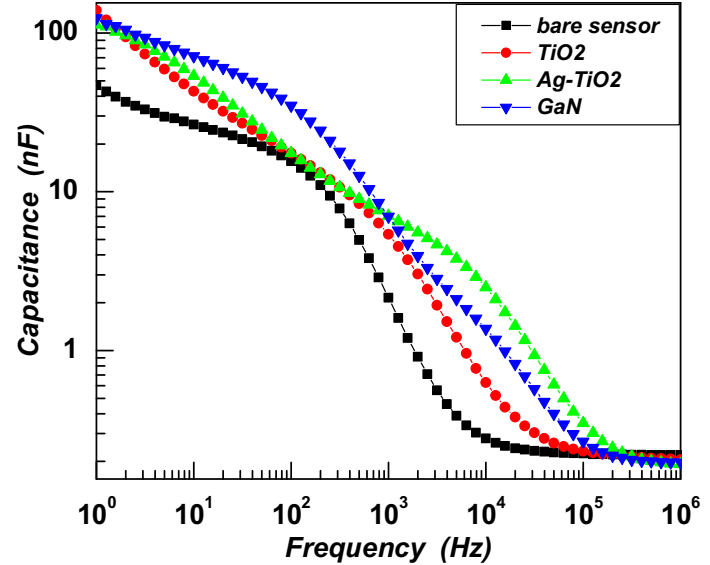

Fig 1. Capacitance response of the sensing units immersed in Milli-Q water.

Anhydrous ethanol(AEF) was obtained directly from the ethanol plant (UNIVALEM, Valparaíso, SP, Brazil), produced from sugar cane and containing $0.4 \%$ vol. of water (as measured in a UNIVALEM laboratory), compliant with Brazilian standards. Hydrous ethanol biofuel (HEF) also supplied by UNIVALEM (4.9\% vol. of water) was used in some measurements. Anhydrous ethanol was mixed with water (Milli-Q or tap water) in different percentages to prepare the mixtures. Samples of hydrous ethanol sold as car biofuel (for flex propelled ethanol/gasoline vehicles) were acquired in different fuel stations and used for blind test measurements. Tap water was collected in Presidente Prudente (SP, Brazil) (maximum content of $0.2 \mathrm{mg} / \mathrm{L}$ of chlorine and $0.7 \mathrm{mg} / \mathrm{L}$ of fluorine for human consumption), following Brazilian standards [32].

\section{Results and discussion}

\subsection{The fingerprint of sensing units}

Fig. 1 exhibits capacitance curves of the sensing units immersed in Milli-Q water. Results obtained after immersing them for $5 \mathrm{~min}$ in the Milli-Q water indicate that the presence of films on interdigitated electrodes alters the response of the bare IDE, creating a fingerprint of the liquid under analysis [29]. The capacitance spectrum varied with the film deposited in practically all frequency regions, probably reflecting the different dielectric constants of the thin films. At very high frequencies (near $1 \mathrm{MHz}$ ) there was almost no change in capacitance because the geometry of the IDEs was the same.

Fig. 2 shows measured capacitances with sensing units immersed in anhydrous ethanol. At $1 \mathrm{kHz}$ a $0.3 \mathrm{nF}$ variation is observed, smaller than that in Fig. 1, indicating a lower sensitivity of the system to ethanol. As the sensing units are more sensitive to water than ethanol, we took it as a tool to determine the water content in ethanol/water mixtures.

The electrical response of the $\mathrm{TiO}_{2}$ thin film at distinct $\mathrm{AEF} / \mathrm{Milli}$ Q water concentrations (from 5 to $60 \%$ vol. of water added in AEF) is illustrated in Fig. 3, which also includes the result for the ethanol fuel (HEF, $4.9 \%$ vol. of water) for comparison. Similar fingerprints were observed (not shown here) for the other sensing units immersed in these AEF/Milli-Q water mixtures. The response at high frequencies $(>100 \mathrm{kHz})$ is due to the capacitive response of ethanol/water mixtures, where capacitance increased with the water content owing to the higher dielectric constant for water (at room temperature $\varepsilon=80$ for water and 25 for ethanol). 


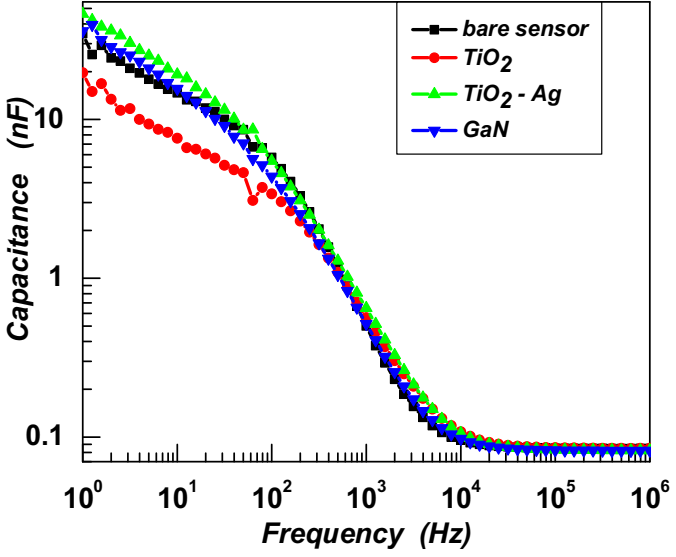

Fig. 2. Capacitance measurements of the sensing units immersed in anhydrous ethanol (AEF).

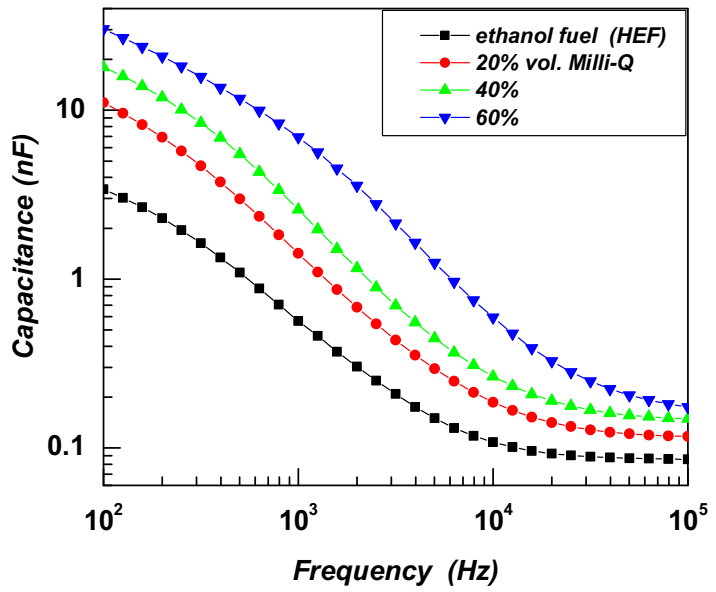

Fig. 3. Capacitance measurements acquired with $\mathrm{TiO}_{2}$ thin film in different AEF/Milli-Q water concentrations, also including the curve for ethanol fuel (HEF).

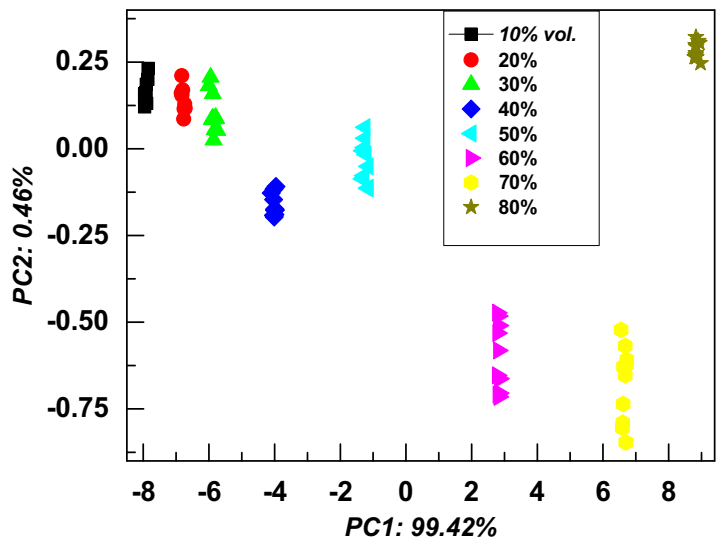

Fig. 4. PCA plot for the electrical capacitance of anhydrous ethanol AEF and Milli-Q water, containing from 10 to $80 \%$ of water.

\subsection{E-tongue measurements-mixtures of Milli-Q water and ethanol}

Fig. 4 shows the PCA plot for capacitances at $1 \mathrm{kHz}$ in AEF/Milli$Q$ water mixtures varying from 10 to $80 \%$ vol. For each mixture a set of 10 independent capacitance measurements were performed in all sensing units, corresponding to the cluster points in the PCA plot of Fig. 4. These results show the e-tongue capability to separate

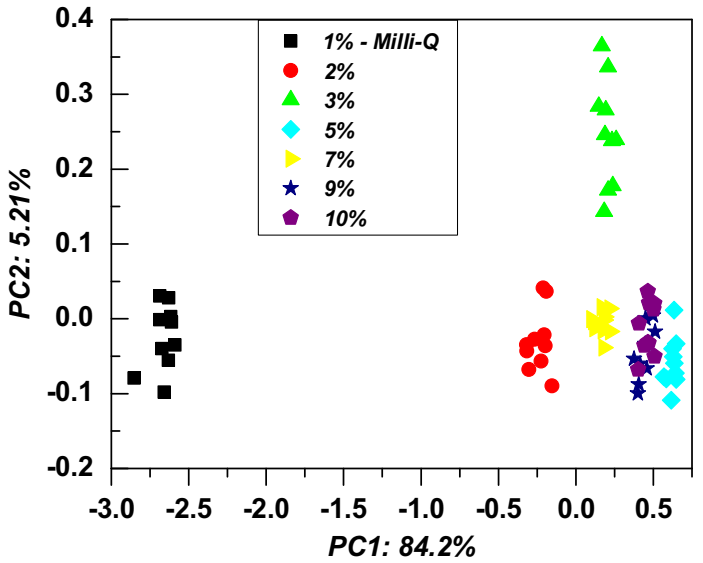

Fig. 5. PCA plot for capacitance for anhydrous ethanol AEF and Milli-Q water containing from 1 to $10 \%$ of water.

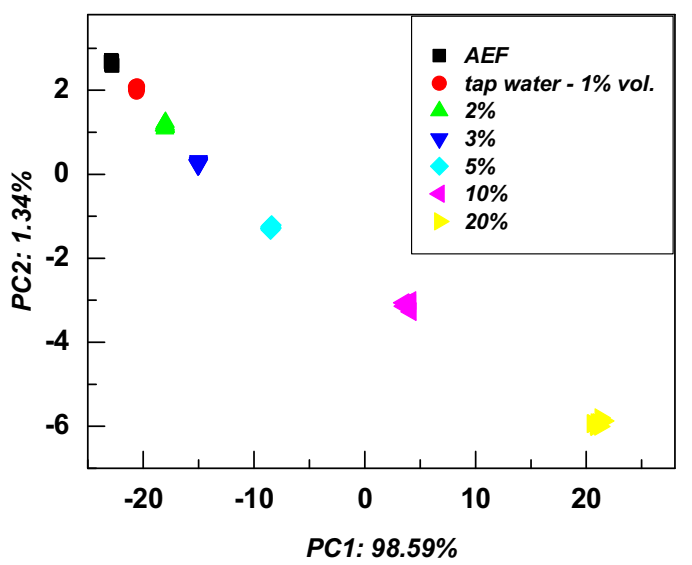

Fig. 6. PCA plot for anhydrous ethanol AEF mixtures containing from 1 to $20 \%$ of tap water.

the mixtures, with a shift to the right as the water content in the mixtures is increased. It is worth mentioning that $99 \%$ of the dispersion in the data could be accounted for by the PC1 component, indicating a high correlation of the data.

Mixtures of AEF/Milli-Q water from 1 to $10 \%$ vol. of added water are illustrated in Fig. 5, with the PCA indicating that the e-tongue system does not discriminate mixtures clearly, since some clusters do not follow a regular trend and merge with each other, clearly indicating a poor discrimination of the samples.

\subsection{E-tongue measurements-mixtures of tap water and ethanol}

In contrast to the lack of discrimination of AEF/Milli-Q water mixtures containing small contents of ultrapure water in Fig. 5, we observed that the addition of small amounts of tap water could be easily determined. Fig. 6 shows this clear distinction in the PCA plot, with both PC1 and PC2 components presenting a regular trend with the additional tap water content. Note also that the data for the same water content in the PCA plot are not scattered, thus indicating good reproducibility for ten measurements with each mixture. The correlation between the PC1 component and the tap water content is readily apparent. The reason why mixtures with tap water (Fig. 6) could be distinguished, while those containing ultrapure water (Fig. 5) could not, is the presence of chlorine, fluorine and carbonates in tap water. This ionic character of tap water affects the double-layer at the electrode/electrolyte interface, making it 


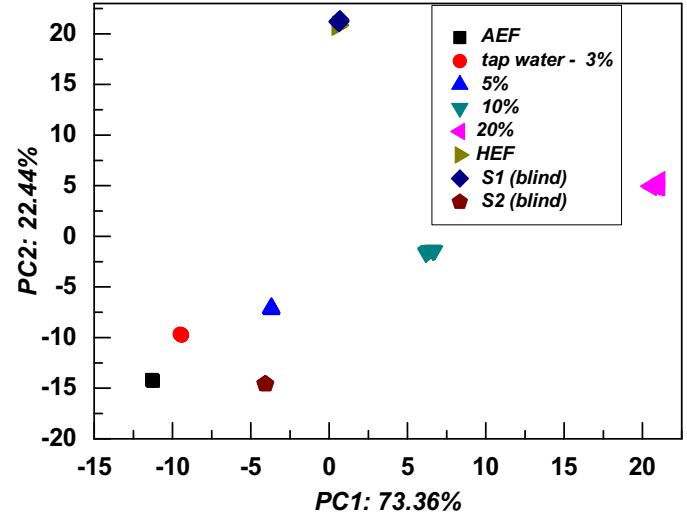

Fig. 7. PCA plot showing in detail differences detected in AEF, HEF, ethanol mixtures with tap water and two ethanol biofuel samples $(\mathrm{S} 1, \mathrm{~S} 2)$ collected from gas stations (blind samples).

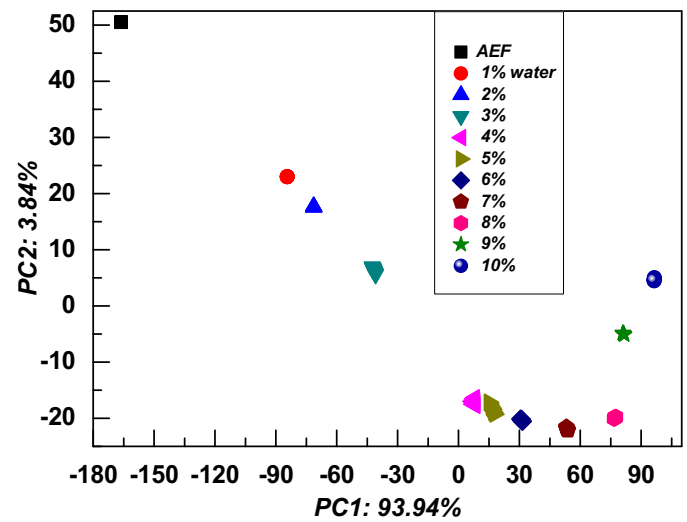

Fig. 8. PCA plot showing in detail the differences detected in ethanol/water mixtures saturated with $\mathrm{NaCl}$.

possible to distinguish the different amounts of tap water as the ionic concentration varies.

Fig. 7 shows the PCA plot for AEF, HEF, mixtures of AEF/tap water (contents of 3, 5, 10 and 20\% vol.) and measurements for two blind samples of ethanol HEF purchased from gas stations. All samples are easily distinguished with a right hand trend as the added water content increased in the mixed samples. Also important is the position of the sample HEF (UNIVALEM fuel, with $4.9 \%$ vol. of water), which almost coincides with the blind sample S1. Furthermore, its PC1 value, which correlates well with the amount of water, is between 5 and $10 \%$ vol. of tap water. The blind sample S2 has PC1 coinciding with the $5 \%$ vol. of tap water. Therefore, the two blind samples appear to be within the specification.

\subsection{E-tongue measurements-mixtures of water-ethanol and $\mathrm{NaCl}$}

The importance of ions to facilitate distinction of samples with added water was confirmed with experiments in which $\mathrm{NaCl}$ was added to ethanol/Milli-Q water mixtures. Fig. 8 shows the PCA plot for capacitance data obtained with these mixtures with saturated $\mathrm{NaCl}$. Samples with distinct water contents are easily distinguished, with the water content being correlated with PC1. We also found in subsidiary measurements that good distinction could be obtained by adding very small amounts of $\mathrm{NaCl}$ at one millimolar (not shown here), rather than saturating with $\mathrm{NaCl}$. Considering the results for tap water as well, we conclude that the contents of water in ethanol mixtures can be easily determined provided that some ions are

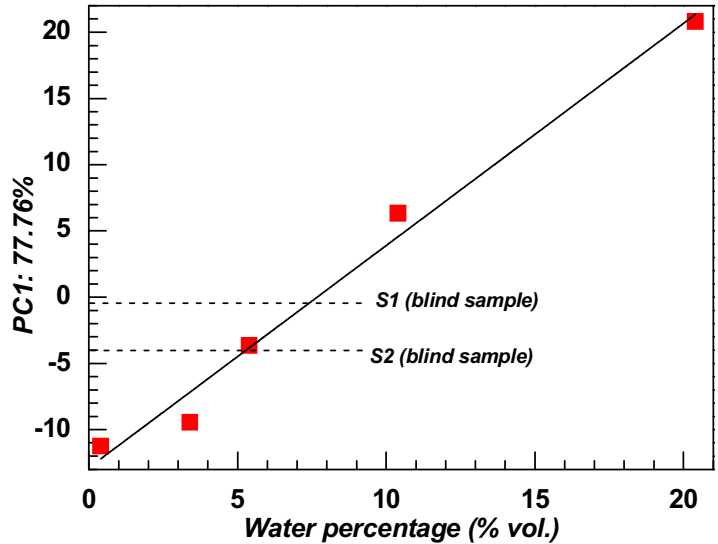

Fig. 9. PC1component versus the tap water percentage (squares). The line is the fitting of points obtained from AEF and AEF-water mixtures. Horizontal lines represents the PC1 values for the blind samples S1 and S2 (ethanol biofuel from gas stations).

present in the water, making it a straightforward method to detect adulteration by water in on-site measurements in gas stations.

\subsection{Determination of water content in ethanol}

The analysis of the data above indicated clearly that PC1 is correlated with the water content, and this has been used to determine quantitatively the water content in several samples to compare with a blind test. Fig. 9 shows that PC1, taken from an average of ten measurements for each sample, varies practically linearly with the amount of tap water added to ethanol. The sample with smallest water content was AEF (with no added tap water), which is known to already contain $0.4 \%$ vol. of water. Note that the water content for the two blind samples of ethanol biofuel purchased from a gas station is 5 and $7 \%$ for $\mathrm{S} 1$ and S2, respectively. Considering the accuracy of this prediction of water content, which should not be higher than $\sim 1 \%$, these samples seem to comply with the Brazilian legislation, according to which the maximum water content should be $6.5 \%$. Our system is therefore capable of detecting adulteration in ethanol biofuel, as the most common type of adulteration is addition of tap water or other kind of non-pure liquid substances.

\section{Conclusions}

The e-tongue developed here is capable of discriminating ethanol and its mixtures with water employing the PCA analysis, particularly when the water contains ions, as is the case of tap water. This is attributed to the ionic character of impurities of tap water (fluorine, chlorine and carbonates) and $\mathrm{NaCl}$ solutions, affecting the double layer formed at the electrode/electrolyte interface. Concerning the e-tongue for practical use, we showed it to be possible to determine the water percentage in the range $0-20 \%$ vol. in ethanol biofuel using a "calibration curve" originating from the linear relationship between the PC1 component and the water content. To improve the accuracy in this determination, progress needs to be made in several areas. For example, one could optimize the use of salt in the mixtures, and use many ethanol and blind samples to establish a precise dependence of PC1 on \% of water. Other parameters to consider are the effect of contamination of ethanol in gas station storage tanks; the importance of different kinds of impurities, and effect of addition of methanol which is prohibited in Brazil. For outdoor applications, one should take into account possible variation in the temperature which may affect the capacitance measurements, since temperature will not be controlled as in laboratory measurements. With regard to data 
processing, different data analysis methods, such as artificial neural networks or data mining [33] could be employed.

The e-tongue developed here uses sensing units fabricated using interdigitated electrodes covered with inorganic thin films of $\mathrm{TiO}_{2}$ and GaN. Such thin films resist to the chemical ethanol attack and are very stable, thus being suitable for practical applications. Attempts to use polymeric films failed since thin organic films are dissolved after several hours or days of immersion in ethanol. The search for new inorganic or even organic materials to fabricate other kinds of sensing units is still a challenge to improve the etongue quality and the water percentage determination. Because ethanol biofuels have been used in many countries as alternative combustible source, classifying them becomes an important issue.

\section{Acknowledgments}

Authors thank UNIVALEM (SP, Brazil) for kindly supplying the anhydrous and hydrous ethanol and FAPESP, CAPES and CNPQ for the financial support. The authors also thank Prof. Osvaldo N. Oliveira Jr for revising the manuscript.

\section{References}

[1] Y.G. Vlasov, A. Legin, A. Rudnitskaya, C. Di Natale, A. D’Amico, Nonspecific sensor arrays (electronic tongue) for chemical analysis of liquids (IUPAC Technical Report), Pure Appl. Chem. 77 (2005) 1965-1983.

[2] A.K. Deisingh, D.C. Stone, M. Thompson, Applications of electronic noses and tongues in food analysis, Int. J. Food Sci. Technol. 39 (2004) 587-604.

[3] A. Legin, A. Rudnitskaya, D. Clapham, B. Seleznev, K. Lord, Y. Vlasov, Electronic tongue for pharmaceutical analytics: quantification of tastes and masking effects, Anal. Bioanal. Chem. 380 (2004) 36-45.

[4] Y. Miyanaga, N. Inoue, A. Ohnishi, E. Fujisawa, M. Yamaguchi, Uchida T. Quantitative prediction of the bitterness suppression of elemental diets by various flavors using a taste sensor, Pharm. Res. 20 (2003) 1932-1938.

[5] Y.G. Vlasov, A. Legin, A. Rudnitskaya, Electronic tongues and their analytical application, Anal. Bioanal. Chem. 373 (2002) 136-146.

[6] J.A. Ragazzo-Sancheza, P. Chalier, S. Chevalier, M. Calderon-Santoy, C. Ghommidh, Identification of different alcoholic beverages by electronic nose coupled to GC, Sens. Actuators B 134 (2008) 43-48.

[7] L. Lvova, R. Paolesse, C. Di Natale, A. D’Amico, Detection of alcohols in beverages: an application of porphyrin-based Electronic tongue, Sens. Actuators B 118 (2006) 439-447.

[8] L.A. Dias, A.M. Peres, A.C.A. Veloso, F.S. Reis, M. Vilas-Boas, A.A.S.C. Machado, An electronic tongue taste evaluation: identification of goat milk adulteration with bovine milk, Sens. Actuators B 136 (2009) 209-217.

[9] K. Toko, Electronic sensing of tastes, Electroanalysis 10 (1998) 657-669.

[10] K. Toko, Biosensors and bioelectronics, Electron. Tongue 13 (1998) 701-709.

[11] K. Toko, A taste sensor, Meas. Sci. Technol. 9 (1998) 1919-1936.

[12] S. Iiyama, M. Yahiro, K. Toko, Measurements of soy sauce using taste sensor, Sens Actuators B 64 (2000) 205-206.

[13] F. Winquist, S. Holmin, C. Krantz-Rülcker, P. Wide, I. Lundström, A hybrid electronic tongue, Analyt. Chim. Acta 406 (2000) 147-157.

[14] C. Krantz-Rülcker, M. Stenberg, F. Winquist, I. Lundström, Electronic tongues for environmental monitoring based on sensor arrays and pattern recognition: a review, Analyt. Chim. Acta 426 (2001) 217-226.

[15] P. Ivarsson, S. Holmin, N.-E. Höjer, C. Krantz-Rülcker, F. Winquist, Discrimination of tea by means of a voltammetric electronic tongue and different applied waveforms, Sens. Actuators B 76 (2001) 449-454.

[16] C. Soderstrom, F. Winquist, C. Krantz-Rulcker, Recognition of six microbial species with an electronic tongue, Sens. Actuators B 89 (2003) 248-255.

[17] Riul Jr A, Mattoso LHC, Fonseca FJ, Taylor DM, Mello SV, Venâncio VC. Patent, PI 0103502-9, INPI, Brazil.

[18] A. Riul Jr., R.R. Malmegrim, F.J. Fonseca, L.H.C. Mattoso, An artificial taste sensor based on conductive polymers, Artif. Organs 27 (2003) 469-472.

[19] M. Ferreira, C.J.L. Constantino, A. Riul Jr., K. Wohnrath, R.F. Aroca, J.A. Giacometti, O.N. Oliveira Jr., L.H.C. Mattoso, Preparation, characterization and taste sensing properties of Langmuir-Blodgett Films from mixtures of polyaniline and a ruthenium complex, Polymer 44 (2003) 4205-4211.

[20] A. Riul Jr., et al., An artificial taste sensor based on conducting polymers, Biosens. Bioelectron. 18 (2003) 1365-1369.

[21] A. Riul Jr., C.A.R. Dantas, C.M. Miyazaki, O.N. Oliveira Jr., Recent advances in electronic tongues, Analyst 135 (2010), 2453-2453.
[22] Available at <www.anp.gov.br> (accessed 18.08.15.). (Resolução ANP N (19, in Portuguese).

[23] Karl-Fischer method-ASTM E203.

[24] L. Bueno, T.R.L.C. Paixão, A copper interdigitated electrode and chemometrical tools for the discrimination of the adulteration of ethanol fuel with water, Talanta 87 (2011) 210-215.

[25] M.K. Figueiredo, R.P.B. Costa-Felix, L.E. Maggi, A.V. Alvarenga, G.A. Romeiro, Biofuel etanol adulteration detection using an ultrasonic measurement method, Fuel 91 (2012) 209-212.

[26] B.L. Bischoff, M.A. Anderson, Peptization process in the sol-gel preparation of porous anatase (TiO2), Chem. Mater. 7 (1995) 1772-1778.

[27] A.L.J. Pereira, J.V. Lopez, J.H.D. da Silva, A rf magnetron sputtering system for preparation of amorphous GaAs films, Revista Brasileira de Aplicações de Vácuo 22 (2003) 50-53.

[28] D.M. Taylor, A.G. MacDonald, AC admittance of the metal-insulator-electrolyte interface, J. Phys. D: Appl. Phys. 20 (1987) 1277-1283.

[29] A. Riul Jr., A.M. Gallardo Soto, S.V. Mello, S. Bone, D.M. Taylor, L.H.C. Mattoso, An electronic tongue using polypyrrole and polyaniline, Synth. Met. 132 (2003) 109-116

[30] H. Hotelling, Analysis of a complex of statistical variables into principal components, J. Educ. Psychol. 24 (1933) 417-441.

[31] Giacometti JA, Riul A, Bergamo BB, Cabral FPA, A setup for an electronic tongue. Patent Number: PI0700292-0, Brazil.

[32] Available at <www.sabesp.com.br>. (accessed on 18.08.2015.). (Portaria N 2.914, in Portuguese).

[33] M.Y. Kiang, A comparative assessment of classification methods, Decis. Support Syst. 35 (2003) 441-454.

\section{Biographies}

Dalton Pedroso de Queiroz Dalton Pedroso de Queiroz is a lecturer at the Universidade Estadual de Mato Grosso do Sul (UEMS), Dourados, Brazil. He received his $\mathrm{PhD}$. in material science and engineering from the Universidade Estadual Paulista (UNESP), campus Presidente Prudente, Brazil, in 2009. His research interests are automation, robotics, sensors and on materials applications.

Ariovaldo de Oliveira Florentino (in memoriam) Ariovaldo de Oliveira Florentino was a lecturer at the Universidade Estadual Paulista (UNESP), campus Botucatu, Brazil. He received his PhD. in chemistry from the Universidade de São Paulo (USP), campus São Carlos, in 1993. His research interest was in physical chemistry of sol-gel materials, catalyzers, photo catalyze $\mathrm{N}^{\circ}$ rs and their characterization. Until 2008 he had authored 40 paper in refereed journals.

Juliana Catarina Bruno Juliana Catarina Bruno is at the Instituto Superior de Ciências Aplicadas, Limeira, Brazil. She received his M.Sc. in chemistry from the Universidade Estadual Paulista (UNESP), campus Araraquara, Brazil, in 2008. She authored over 14 papers in refereed journals. Her interests are teaching and research on physics-chemistry and materials characterization.

José Humberto Dias Silva José Humberto Dias Silva is a lecturer at the Universidade Estadual Paulista (UNESP), campus Bauru, Brazil. He received his PhD. in physics from the Universidade Estadual de Campinas (UNICAMP), Brazil, in 1994 with two years of post-doctoral at University of Utah, USA. He has authored over 40 papers in refereed journals. His scientific research is physics and material science mainly related with grow, structural and optical properties of films and semiconductor nanostructures.

Antonio Riul Jr. Antonio Riul Jr. is a lecturer at the University of Campinas (UNICAMP), Campinas, Brazil. He obtained his PhD. in Materials Science and Engineering from Universidade de São Paulo (USP, São Carlos-Brazil) in 1988, with two years of post-doctoral experience at the University of Wales (Bangor, UK). Since then he has studied ultra-thin films of organic materials for development of electronic tongues using impedance spectroscopy, publishing the first paper involving conducting polymers in this sort of application. He also authored over 59 papers, and filed 3 patents.

José Alberto Giacometti José Alberto Giacometti was full professor at the Universidade Estadual Paulista (UNESP), campus Presidente Prudente, Brazil and retired after 2012. He obtained his PhD in physics from the Universidade de São Paulo (USP), campuis São Carlos, Brazil, in 1982. Actually, he is at the Institute of Physics of São Carlos (USP, São Carlos-Brazil) as visiting researcher. He worked on the field of dielectric materials with important contributions to the corona charging of dielectric films. He has studied thin films of organic materials for organic electronics and photoinduced birefringence. He authored over 110 papers, filed 3 patents and supervised over 38 PhD. and M.Sc. students. 